\title{
NEEDLE STICK INJURIES: A STUDY FROM PRIVATE TERTIARY CARE CENTRE OF MARATHWADA REGION IN MAHARASHTRA
}

Sonkar V.K ${ }^{1}$ Madne R.D², Inamdar I.F³, Doibale M.K

1. Assistant Professor, Department of Community Medicine, Dr. S.C. Government Medical College, Nanded,

2. Consultant Physician, Department of Community Medicine, AADHAR Hospital, Nanded.

3. Assistant Professor, Department of Community Medicine, Dr. S.C. Government Medical College, Nanded.

4. Professor and Head, Department of Community Medicine, Dr. S.C. Government Medical College, Nanded.

\section{CORRESPONDING AUTHOR}

Dr. Inamdar I.F.,

In-charge, Urban Health Training Centre,

Near Police Station,

Shivaji Nagar, Nanded-431602

Maharashtra.

Email- ifinamdar@rediffmail.com

\section{HOW TO CITE THIS ARTICLE:}

Sonkar V.K, Madne R.D, Inamdar I.F, Doibale M.K. "Needle stick Injuries: A Study from Private Tertiary Care Centre of Marathwada Region in Maharashtra". Journal of Evolution of Medical and Dental Sciences 2013; Vol2, Issue 23, June 10; Page: 4189-4198.

ABSTRACT:- INTRODUCTION: Needle stick injuries are one of the greatest risks faced by the front line healthcare workers in the light of HIV/ AIDS, Hepatitis B and C. Yet, these exposures have often been considered as part of the job and neglected. OBJECTIVE: 1 . To study prevalence of needle stick injury among health care workers of a private tertiary care hospital. 2. To assess the knowledge, attitude and practices of needle stick injury among them.

METHODOLOGY: Hospital based cross sectional study was carried out with preformed pretested questionnaire on all (42) health care workers of a private tertiary care hospital. RESULTS: Results showed that out of 42 subjects $35(83.3 \%$ ) had a history of needle-stick injury but only $11 \%$ reported the injuries to the hospital authority and received PEP prophylaxis against HIV. Only 11 HCW's (26.2\%) were aware about where to report the NSI incident. $4.8 \%$ and $95.3 \%$ of health care workers, respectively, were unaware of the fact that hepatitis B and hepatitis C can be transmitted by needle-stick injuries. Only $21.5 \%$ were in the habit of using gloves for phlebotomy procedures all the time. $40.5 \%$ were of the impression that needle should not be recapped after use but $21.5 \%$ of them didn't implement it. Only 38.1\% were aware of Universal Precaution Guidelines. 18 subjects $(42.9 \%)$ had been vaccinated against hepatitis B; while 26 subjects (47.6\%) were not vaccinated against hepatitis B.23 subjects (54.8\%) knowing their HBsAg status. Majority of HCW (95.3\%) were demanding training and awareness of NSI.

CONCLUSION: The study revealed that knowledge among health care workers about the risk associated with needle-stick injuries and use of preventive measures was inadequate. Standard operating procedure (SOP) should be formulated and followed by them.

KEY WORDS: Needle stick injury (NSI), Post Exposure prophylaxis (PEP), health care worker (HCW), 
INTRODUCTION: Everyday healthcare workers are exposed to dangerous and deadly blood-borne pathogens and are at risk of occupational acquisitions of blood-borne illnesses. Occupational exposure to blood-borne pathogens among healthcare workers include percutaneous exposure to needles and other sharp objects, and mucocutaneous exposure that is contact with intact or non intact skin with mucous membranes.

In the healthcare settings, percutaneous injuries are the most common form of occupational exposures and most likely to result in infection. The level of risk depends on the number of patients with that infection in the health care facility and the precautions the health care workers observe while dealing these patients.

A needle stick injury is a percutaneous piercing wound typically set by a needle point, but possibly also by other sharp instruments or objects. Commonly encountered by people handling needles in the medical setting, such injuries are occupational hazards in the medical community ${ }^{[1]}$.

WHO'S Environmental Burden of Disease Series, No. 11published in 2005[2] states that Among the 35 million health workers worldwide, about 3 million experience percutaneous exposures to blood borne pathogens each year; two million of those to HBV, 0.9 million to HCV and 170000 to HIV. These injuries may result in $15000 \mathrm{HCV}, 70000 \mathrm{HBV}$ and $1000 \mathrm{HIV}$ infections. More than $90 \%$ of these infections occur in developing countries.

It further notes that $37.6 \%$ of Hepatitis B, 39\% of Hepatitis C and $4.4 \%$ of HIV/AIDS in Health-Care Workers around the world are due to needle stick injuries and these rates for south east Asia region are 42\%,52\% and 7.9\% respectively, For India, a rapid assessment survey states that 2.27 Sharps injuries per health-care worker per year. ${ }^{[2]}$

U.S. EPINet Sharps Injury Data Report for 2011says that among 32 hospitals that contributed data 708 total injuries had occurred; Percutaneous injury (PI) rate for all hospitals was 19.46 per 100 occupied beds; most of the incidents occurred at operation theatre $33.5 \%$ and patient ward 33.2\%; majority of injuries were caused by disposable syringes (37.4\%) and by suturing needle(18.6\%); most of the injuries occurred during use $(40.7 \%)$ of item and after use but before disposal $(15.5 \%)^{[3]}$

Most of the studies done in India are either done in government hospital or teaching institutions and in urban settings; this study was undertaken to estimate needle stick injuries in a private tertiary care hospital and to assess knowledge, attitude and practice related to needle stick injuries among them.

MATERIAL AND METHODS: A hospital based cross sectional study carried out at a Nanded city, which is second largest city in Marathwada region of Maharashtra. As city is strategically located at Maharashtra-Andhra Pradesh and Karnataka border; flow of patients seeking care is much more and to deliver health care many private tertiary care hospital erupted in this city. We have randomly selected one private tertiary care centre and after due permission from management of the hospital, study was carried out. This tertiary care hospital is 70 bedded hospital having specialties in general medicine, orthopedics, obstetrics and gynecology department. There were 42 health care workers (HCWs), working in the hospital. All of the HCWs were fully explained regarding pattern and purpose of the study and agreed to participate in the study with duly written informed consent. A predesigned and pretested semi closed ended questionnaire was administered 
to collect the data about their demographic information, needle stick injury experience and knowledge, attitude and practice about needle stick injuries. Data was entered in Microsoft's office excel sheet and analyzed.

Case definition of NSI in the present study included injuries caused by sharps such as hypodermic needles, blood collection needles, I.V. cannula, suture needles, winged needle I.V. sets and needles used to connect parts of the I.V. delivery systems.

RESULT: Demographic profile of health care worker shows that out of 42 subjects enrolled in study21were male HCW and 21were female health care workers; in which $6(14.2 \%)$ were consultants, 8(19\%) Residential Medical Officers while others include 14(33.4\%) nursing staff and $14(33.4 \%)$ technical staff.

Majority of HCWs 22 (52.38\%) belongs to 18 to 25 years age group,17 (40.47\%) healthcare workers were in 26 to 35 age groups and only 3(7.15\%) were in 36 to 45 years age group.

In this tertiary care center $10(23.8 \%)$ HCWs were having work experience of less than one year, 20(47.6\%) HCWs have work experience between 1-5 years and 12(28.6\%) HCWs have work experience of more than 5 years.

Out of 42 HCW's, 38(90.4\%) HCWs were aware about the fact that HIV/AIDS and 40 (95.2\%) hepatitis B were transmitted by needle stick injury (NSI). Only 2 (4.7\%) healthcare workers know that diseases like Hepatitis $\mathrm{C}$ and others were transmitted by NSI.

Many of the healthcare workers $31(73.8 \%)$ do not know where to report the NSI incident in Nanded district while 11 (26.2\%) HCWs were aware about the NSI reporting center.

Only $24(57.1 \%)$ HCWs were fully aware of the term post exposure prophylaxis (PEP) and $11(26.1 \%)$ HCWs not fully aware of PEP while 7(16.6\%) were totally blank about PEP term.

Out of 35 healthcare workers who were aware about PEP only 7(20\%) know basic regime of PEP received for HIV and 28 (80\%) HCWs unaware of basic regime for HIV post exposure prophylaxis.

Out of 42 HCWs, 16(38.1\%) were completely aware of Universal Precaution Guidelines (UPG), 16 (38.1\%) were partially aware of UPG and 10 (23.8\%) HCWs were totally unaware about UPG recommended by CDC authority.

Most of the healthcare workers i.e.35 (83.4\%) had experienced needle stick injury in the past while only 7 (16.6\%) were not having experience of NSI.

Job category wise consultants doctors has incidence of NSI i.e.4 (66.66\%) while RMO's having $7(87.5 \%)$ and nursing staff $11(78.57 \%)$ and other technical staff $13(92.85 \%)$.

Gender wise risk of NSI is high among males 19 (90.47\%) compared to females in which it is 16(76.19\%).

Out of 35 healthcare workers who had past experience of NSI, 25(71.42\%) HCWs experienced 1-2 times, 5 (14.29\%) were 3-4 times and 5 (14.29\%) were more than 5 times NSI per year.

Out of 35 healthcare workers who had past experience of NSI, only 4(11\%) HCWs reported NSI incident to reporting authority and received PEP for HIV prophylaxis

Almost 31(89\%) HCWs had not reported it and not received any PEP for HIV and HBV. 
Out of 42 HCWs, $18(42.9 \%)$ have taken complete course of HBV vaccination, $4(9.5 \%)$ HCWs had not completed three doses schedule of HBV vaccine and 20 (47.6\%) HCWs were not received HBV vaccine at all.

On history, only $1(2.4 \%)$ healthcare worker was found to be HBsAg positive and $18(42.8 \%)$ HCWs were negative for HBsAg while 23 (54.8\%) HCWs had not tested there HBsAg status.

Majority of HCWs i.e.25 (59.5\%) were still in favor and only 8(19\%) were against of recapping the needle after phlebotomy while 9 (21.5\%) HCWs were still practicing of recapping of needle after phlebotomy even after they were aware about not to do so.

Out of 42 HCWs only $9(21.5 \%)$ always wears gloves while phlebotomy and other procedures, while majority of HCWs $27(64.3 \%)$ not practice it always and only $6(14.2 \%)$ HCWs don't practice wearing of gloves at all.

Most of the healthcare workers $40(95.3 \%)$ was in demand for increasing awareness of Needle stick injury (NSI) and only 2(4.7\%) no more awareness regarding NSI.

DISCUSSION: Avoiding occupational blood exposures is the primary way to prevent transmission of hepatitis B virus (HBV), hepatitis C virus (HCV) and human immunodeficiency virus (HIV) in healthcare settings. [5]

However, hepatitis B immunization, universal precautions and postexposure management are integral components of a complete program to prevent infection following bloodborne pathogen exposure and are important elements of workplace safety. ${ }^{6]}$

In this study total 42 healthcare workers were participated including consultants $6(14.2 \%)$, RMO's 8(19\%) and nursing \& technical staff 28(66.6\%), Many similar studies has been carried out such as Gurubhacharya et al[7],Wig et al[8] and Chogle et al[9] on the needle sticks injuries causing as a part of occupational hazard of HCW including doctors, interns, technicians and nurses.

In this study, majority of HCW's were working in the healthcare more than three years $32(76.2 \%)$ and 10 health care workers were working experience of less than one year while Salekar et al[10] did not included any HCW having working experience less than one year. Factors such as Working experience, adequate training, type of procedure, action taken following injury are helpful for HCW in preventing transmission of infection through NSI. In this study, the 42 HCWs who participated $90.4 \%$ were aware of the fact that HIV/AIDS can be transmitted by needle-stick injury, but $4.8 \%$ for $\mathrm{HBV}$ and $95.3 \%$ for $\mathrm{HCV}$ not aware of transmission through NSI, where as in Gurubhacharya et al [7] study it is $4 \%$ and $61 \%$ for HBV and HCV transmission.

A data combined from more than 20 prospective studies worldwide of health care workers exposed to HIV-infected blood through percutaneous injury revealed an average transmission rate of $0.3 \%$ per injury.[11] Majority of HCW in this study 38(90.4\%) aware that HIV/AIDS is transmitted by NSI but $4(9.6 \%)$ HCW's were still not aware of this fact.

The present study shows that 35(83.4\%) HCWs have had occupational exposure of NSI. This figure is matching with $79.4 \%$ stated in the study by Wig et ${ }^{[8]}, 80 \%$ of HCW having NSI in Murlidhar et $a l^{[4]}$ and much higher than the $18.09 \%$ in the study of Baheti et al[12] and 34\% documented by Scoular et al [13].

Stein et al[14] stated that $37 \%$ of the respondents (doctors and nurses) had suffered a needle-stick injury with a used needle, with doctors more likely to be injured than nurses.

Our study also showing similar results that incidence of NSI is found to be highest with RMO's 87.5\%(7) while it is lower in nursing \& technical staff i.e.85.71\%(24) and lowest in 


\section{ORIGINAL ARTICLE}

consultants 66.66\%(4) in contrast to this Baheti et al[12] study showing higher rate in nurses(19.4\%) than doctors(18\%). Several other studies had also shown high occurrence of NSI among nurses. [15-16] Apart from nurses the NSIs were more among nursing students, interns and resident doctors.

As far as gender distribution our study shows prevalence of NSI is more in males $90.47 \%$ (19) than females $76.19 \%$ (16) similar to Salelkar et al [10] showing NSI in males $36.2 \%$ and in females $34.2 \%$. Though the working environment and opportunity are equal to both the genders, this gender variation is unexplained and requires more studies.

In Gurubhacharya et al [7] study, Of the 52(74\%) health care workers with a history of needle stick injuries, 41(79\%) never reported the incident to hospital authority to get postexposure treatment because they were not aware of the importance of post-exposure prophylaxis. Similarly in our study, large amount of HCW's (89\%) not reported NSI incident to reporting authority where as in Makary et al [17] study this percentage of not reporting of NSI is less i.e.50\%. The reason behind not reporting NSI to reporting center is lack of time for consultant doctors and lack of awareness in nursing staff as almost $42.8 \% \mathrm{HCW}$ in this study were not fully aware of post exposure prophylaxis, hence educating HCW regarding NSI may be useful for their better healthy working pattern. This lack of awareness of PEP is not only seen in our study but also proved by other studies done across many corners of the world.

The fact that PEP should be started as soon as possible (within 2 hours after exposure as per hospital guidelines) was known by $74.01 \%$ doctors, as against $36 \%$ and $64 \%$ reported by $\mathrm{Wig}$ et al [8] and Chogle et al [9], In our study maximum HCW's $78.57 \%$ were in favor of starting PEP within 24 hrs of exposure, 11.9 say in 48 hrs and 9.8\% told in 72 hrs. Similarly, Siwach et al [18] surveyed 123 residents of various surgical specialties at the Post Graduate Institute of Medical Education and Research, Chandigarh and found that $70 \%$ of the respondents were not aware of the availability of post-exposure prophylaxis, and most of them were not sure of the timing of its administration. This suggests that inspite of clear guidelines HCW's are ignoring to report the incident of NSI and receiving PEP.

Knowledge about the basic regimens of PEP was only $20 \%$ in our study where as Baheti et $a^{[12]}$ shows it is $35.19 \%$. This is more than the $8 \%$ reported by Chen et al[19] similarly Chogle et al[9] documented that $42 \%$ were aware of the use of zidovudine but none were aware of the second (basic) or third (expanded) drugs used for PEP. Scoular et al too reported that only 13\% respondents knew that a regimen consisting of more than one drug is now recommended. strategies for the betterment in knowledge about basic regime of PEP for HIV in HCW's should include better sensitization of availability of institutional guidelines, prior experience of self/ peers as well as training on the subject of PEP.

Our study indicates that $73.8 \%$ HCWs are aware of whom to contact after a needle-stick injury to obtain PEP. In the study conducted by Chogle et al[9]]ess than $33 \%$,Baheti et al[12] $55.95 \%$ were aware of this fact, while in that carried out by Duff et al[20] $7.6 \%$ knew about whom to contact. The reasons for better knowledge base in our study population might include availability of institutional guidelines, rising incidence of HIV, prior experience. Availability of institutional guidelines and wide publicity of PEP available in the institution premises is a must for reducing the time interval between the occupational exposure and the first dose taken. 
Our study shows that only $42.9 \%$ HCW's were vaccinated against HBV. This is comparably less than the $87.7 \%$ reported by Wig et al[8] in their study and $87.17 \%$ in Baheti et al [12]study probably due to large number of untrained staff and less awareness regarding importance of HBV vaccine.. The policies should be adapted by the hospital to educate and vaccinate the HCWs regarding HBV vaccination which is more fatal than HIV as for as transmission is concerned. In our study it is found that the healthcare workers were not even keen to test their HBsAg status neither hospital administration as a routine checkup hence almost 54.8\% HCW's working in this hospital remains untested for HBsAg status. The available IEC material in this hospital does not adequately address the issue of PEP knowledge base of HCWs regarding modes of transmission and PEP for Hepatitis B and C viruses.

The circumstances leading to needle stick injury depends upon the type and design of device and certain work practices. This survey revealed that only $21.5 \%$ HCW's always use gloves while phlebotomy and related procedure where as majority $64.3 \%$ were not using regularly and $14.2 \%$ were not using it at all. These findings matches with Gurubhacharya et al[7] study in which $23 \%$ using always and $61 \%$ using sometimes. Salekar et al [10] also reported in his study that 58\% HCWs wearing gloves at the time of injury. Gloves usage was lowest in nurses (46.3\%) and highest amongst consultants (100\%) which is similar to reports of our study in which doctors uses gloves highest (35.7\%) than nursing staff(14\%)but the prevalence of using gloves is remarkably less than

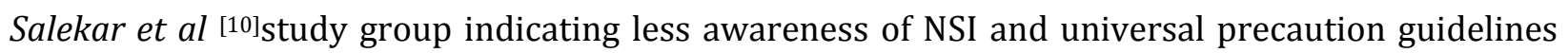
(UPG).

It is documented that $10 \%-25 \%$ injuries occurred while recapping a used needles. ${ }^{[21]}$ The recapping of needles has been prohibited under the Occupational Safety and Health Administration (OSHA) blood borne pathogen standard.[22] In our study 59.5\% were of the impression that needle should be recapped after use, while these figures less than 79\% in Gurubhacharya et al [7]study. In 1985, in order to increase awareness among health care workers of the dangers of sharp injuries and other types of disease transmission, the Centre for Disease Control (CDC) and the Occupational Safety and Health Administration (OSHA) in the United States introduced the "Universal Precaution Guidelines", which have been the worldwide standard in both hospital and community care settings ${ }^{[23]}$. In the present survey, only 16 (38.1\%) HCW's less than Gurubhacharya et al [7] study 46 (66\%) workers were aware of the Universal Precaution Guidelines.

All hospitals should establish a protocol for reporting, counseling and treating of needles tick injuries. Our survey suggests that most respondents were ignorant of its existence, and that knowledge of the protocol needs to be disseminated more widely and effectively. After gauging the level of ignorance in this survey, a copy of the CDC guidelines on post-exposure prophylaxis should be distributed to all health care personnel in local language. In this study 40 (95.3\%) HCW's were demanding detail awareness programme in the hospital as an educational tool for the betterment of HCW. Healthcare employers should establish exposure control protocols for reporting, registration, evaluation, counseling, treatment and follow up of occupational exposure to pathogens including HIV and HBV. Hospital infection control committees must formulate, implement and monitor recommendations, and impart frequent training and education to HCW.

This survey revealed that knowledge of health care workers about the risk associated with needle-stick injuries and use of preventive measures was inadequate. Health care workers should 
be made aware of hazards, preventive measures and post-exposure prophylaxis to needle-stick injuries.

\section{REFERENCES:}

1. Rele M, Mathur M, Turbadkar D. Risk of needle stick injuries in health care workers: A report. Indian J Med Microbiol 2002; 20:206-7.

2. http://www.who.int/mediacentre/factsheets/fs231/en/

3. http://www.healthsystem.virginia.edu/pub/epinet/epinetdatareports.html

4. Muralidhar S, Singh PK, Jain RK, Malhotra M, Bala M. Needle stick injuries among health care workers in tertiary care hospital of India. Indian J Med Res 131, March 2010, pp 405-410.

5. CDC NIOSH alert: preventing needle stick injuries in health care settings. Cincinnati, OH: Department of Health and Human Services, CDC, 1999; DHHS publication no. (NIOSH) 2000108.

6. Department of Labor, Occupational Safety and Health Administration, 29 CFR Part 1910, 1030, Occupational exposure to blood borne pathogens; final rule, Federal Register 1991; $56,64004-182$

7. Gurubhacharya DL, Mathura KC, Karki DB. Knowledge, attitude and practices among health care workers on needle-stick injuries. Kathmandu University Medical Journal (2003) Vol. 1, No. 2, 91-94.

8. Wig N: HIV: awareness of management of occupational exposure in health care workers. Indian J of Med Sci 2003; 57; 5; 192-198.

9. Chogle NL, Chogle MN, Divatia JV, Dasgupta D. Awareness of post-exposure prophylaxis guidelines against occupational exposure to HIV in a Mumbai hospital. Natl Med J India 2002; 15:69-72.

10. Salelkar S, Motghare DD, Kulkarni MS, Vaz FS. Study of needle stick injuries among health care workers at a tertiary care hospital. Indian J PublicHealth2010; 54:18-20.

11. Kermode M, Jolley D, Langkham B, Thomas MS, Crofts N. Occupational exposure to blood and risk of bloodborne virus infection among health care workers in rural north Indian health care settings. Am J Infect Control 2005; 33:34-41.

12. Baheti AD, Tullu MS and Lahiri KR. Awareness of Health Care Workers Regarding Prophylaxis for Prevention of Transmission of Blood-Borne Viral Infections in Occupational Exposures. Al Ame en J Med Sci 2010; 3(1) :79 -83.

13. Scoular A, Watt AD, Watson M, Kelly B. Knowledge and attitudes of hospital staff to occupational exposure to bloodborne viruses. Commun Dis Public Health 2000; 3:247-94.

14. Stein AD, Makarawo TP, Ahmad MF. A survey of doctors' and nurses' knowledge, attitudes and compliance with infection control guidelines in Birmingham teaching hospitals. JHosp Infect 2003; 54:68-73.

15. Ippolito G, Puro V, De Carli G. The risk of occupational human immunodeficiency virus infection in health care workers. The Italian Study Group on Occupational Risk of HI V infection. Arch Intern Med 1993; 153: 1451- 8.

16. Henderson DK. Managing occupational risks of Hepatitis $C$ transmission in the health care setting. Clin Microbiol Rev 2003;16:546-68 
17. Makary MA, Ali MD, Holzmueller CG, Pronovost PJ. Needlestick injuries among surgeons in training.N Engl J Med 2007; 356:2693-2699.

18. Siwach V, Dahiya D, Rao Ch UM, Dhanda R, Sharma A, Minz M. Resident doctors, bloodborne pathogens and universal precautions: are we sitting on a volcano? Natl Med J India 2001. May-Jun;14(3):179.

19. Chen MY, Fox EF and Rogers CA. Post-exposure prophylaxis for human immunodeficiency virus: knowledge and experience of junior doctors. Sex Transm Infect 2001; 77:444-5.

20. Duff SE, Wong CKM, May RE. Surgeons' and occupational health departments' awareness of guideline on PEP for staff exposed to HIV: telephone survey. BMJ 1999; 319: 162.

21. Perry J, Parker G, Jagger J. EPINET report: 2003 percutaneous injury rates. Adv Exposure Prev 2005; 7:2-45.

22. Mehta A, Rodrigues C, Ghag S, Bavi P, Shenai S, Dastur F. Needle stick injuries in a tertiary care centre in Mumbai, India. J Hosp Infect 2005; 60:368-73.

23. Mujeeb AS, Khatri Y, Khanani R. Frequency of parenteral exposure and seroprevalence of HBV, HCV and HIV among operation room personnel. J Hosp Infect 1998; 38: 133-7.

TABLE NO.1 Demographic profile of health care workers:

\begin{tabular}{|c|c|c|c|}
\hline Variables & $\begin{array}{l}\text { Demographic } \\
\text { Characteristics }\end{array}$ & Number of HCWs & Percentage (\%) \\
\hline \multirow{3}{*}{ 1. Age } & $18-25$ yrs & 22 & $52.38 \%$ \\
\hline & $26-35$ yrs & 17 & $40.47 \%$ \\
\hline & $>35$ yrs & 03 & $07.15 \%$ \\
\hline \multirow[t]{2}{*}{ 2. Sex } & Male & 21 & $50 \%$ \\
\hline & Female & 21 & $50 \%$ \\
\hline \multirow[t]{4}{*}{ 3. Job work } & Consultant & 6 & $14.2 \%$ \\
\hline & RMO & 8 & $19.0 \%$ \\
\hline & Nursing staff & 14 & $33.4 \%$ \\
\hline & Technical staff & 14 & $33.4 \%$ \\
\hline \multirow[t]{4}{*}{ 4. Work experience } & $\leq 1 \mathrm{yrs}$ & 10 & $23.8 \%$ \\
\hline & $1-3$ yrs & 08 & $19.0 \%$ \\
\hline & $3-5$ yrs & 12 & $28.6 \%$ \\
\hline & $\geq 5$ yrs & 12 & $28.6 \%$ \\
\hline
\end{tabular}


TABLE NO.2: Characteristics of needle stick injuries (NSI) in health care workers.

\begin{tabular}{|c|c|c|c|}
\hline \multirow[t]{3}{*}{ Needle stick injury experience } & & Number of HCWs & Percentage (\%) \\
\hline & Yes & 35 & $83.4 \%$ \\
\hline & No & 7 & $16.6 \%$ \\
\hline \multirow[t]{5}{*}{ Gender wise NSI } & Male & 19 & $90.5 \%$ \\
\hline & Female & 16 & $76.2 \%$ \\
\hline & Consultants & 4 & $66.6 \%$ \\
\hline & RMOs & 7 & $87.5 \%$ \\
\hline & Nursing \& technical staff & 24 & $85.7 \%$ \\
\hline \multirow[t]{3}{*}{ NSI /person/ Year } & $1-2$ times & 25 & $71.42 \%$ \\
\hline & 3-4 times & 5 & $14.29 \%$ \\
\hline & $\geq 5$ times & 5 & $14.29 \%$ \\
\hline \multirow[t]{2}{*}{ Reporting of NSI } & Yes & 4 & $20.0 \%$ \\
\hline & No & 31 & $80.0 \%$ \\
\hline \multirow[t]{3}{*}{ Treatment after NSI } & PEP received & 4 & $11.0 \%$ \\
\hline & PEP not received & 27 & $78.0 \%$ \\
\hline & Symptomatic & 4 & $11.0 \%$ \\
\hline
\end{tabular}


TABLE N0.3: Knowledge, attitude and practices regarding needle stick injuries and variables.

\begin{tabular}{|c|c|c|c|}
\hline \multirow[t]{4}{*}{$\begin{array}{l}\text { 1. Diseases transmitted by needle stick } \\
\text { injury }\end{array}$} & & $\begin{array}{l}\text { Number of } \\
\text { HCWs }\end{array}$ & $\begin{array}{l}\text { Percentage } \\
(\%)\end{array}$ \\
\hline & HIV/AIDS & 38 & $90.4 \%$ \\
\hline & HBV & 40 & $95.2 \%$ \\
\hline & HCV \& others & 2 & $04.7 \%$ \\
\hline \multirow{3}{*}{$\begin{array}{l}\text { 2. Awareness of Universal precaution } \\
\text { guidelines }\end{array}$} & Complete & 16 & $38.1 \%$ \\
\hline & Partial & 16 & $38.1 \%$ \\
\hline & Unaware & 10 & $23.8 \%$ \\
\hline \multirow[t]{3}{*}{ 3. Use of Gloves } & Always & 9 & $21.5 \%$ \\
\hline & Sometimes & 27 & $64.3 \%$ \\
\hline & Not at all & 6 & $14.2 \%$ \\
\hline \multirow[t]{3}{*}{ 4. Needle recapping } & Against & 8 & $19.0 \%$ \\
\hline & In favour & 25 & $59.5 \%$ \\
\hline & $\begin{array}{l}\text { Against but still } \\
\text { do }\end{array}$ & 9 & $21.5 \%$ \\
\hline \multirow[t]{2}{*}{ 5. NSI reporting centre } & Know & 11 & $26.2 \%$ \\
\hline & Don't know & 31 & $73.8 \%$ \\
\hline \multirow[t]{3}{*}{ 6. PEP } & Fully aware & 24 & $57.2 \%$ \\
\hline & Partially aware & 11 & $26.2 \%$ \\
\hline & Unaware & 7 & $16.6 \%$ \\
\hline \multirow[t]{2}{*}{ 7. Basic regimen of PEP for HIV } & Know & 7 & $20.0 \%$ \\
\hline & Don't know & 28 & $80.0 \%$ \\
\hline \multirow[t]{3}{*}{ 8. HBV vaccination status } & Complete & 18 & $42.9 \%$ \\
\hline & Incomplete & 4 & $9.5 \%$ \\
\hline & Not taken & 20 & $47.6 \%$ \\
\hline \multirow[t]{3}{*}{ 9. HBs Ag status } & Positive & 1 & $2.4 \%$ \\
\hline & Negative & 18 & $42.8 \%$ \\
\hline & Don't know & 23 & $54.8 \%$ \\
\hline \multirow[t]{2}{*}{ 10. NSI awareness } & Require & 40 & $95.3 \%$ \\
\hline & Doesn't require & 2 & $4.7 \%$ \\
\hline
\end{tabular}

